Pacific Journal of Mathematics

SUMMABILITY OF DERIVED CONJUGATE SERIES 


\section{SUMMABILITY OF DERIVED CONJUGATE SERIES}

\section{B. J. BOYER}

1. Introduction. In a recent paper ([3] it was shown that the summability of the successively derived Fourier series of a $C P$ integrable function could be characterized by that of the Fourier series of another $C P$ integrable function. It is the purpose of the present paper to give analogous theorems for the successively derived conjugate series of a Fourier series.

2. Definitions. The terminology used in [3] will be continued in this paper. In addition let us define:

$$
\psi(t)=\psi(t, r, x)=\frac{1}{2}\left[f(x+t)+(-1)^{r-1} f(x-t)\right]
$$

$$
\begin{aligned}
Q(t) & =\sum_{i=0}^{\left[\frac{r-1}{2}\right]} \frac{\bar{a}_{r-1-2 i}}{(r-1-2 i) !} t^{r-1-2 i} \\
g(t) & =r ! t^{-r}[\psi(t)-Q(t)]
\end{aligned}
$$

The $r$ th derived conjugate series of the Fourier series of $f(t)$ at $t=x$ will be denoted by $D_{r} C F S f(x)$, and the $n$th mean of order $(\alpha, \beta)$ of $D_{r} C F S f(x)$ by $\bar{S}_{\alpha, \beta}^{r}(f, x, n)$.

\section{Lemmas.}

LeMmA 1. For $\alpha=0, \beta>1$ or $\alpha>0, \beta \geqq 0$, and $r \geqq 0$,

$$
\begin{gathered}
\bar{\lambda}_{1+\alpha, \beta}^{(r)}(x)=-\pi^{-1} r !(-x)^{r+1}+0\left(|x|^{-1-\alpha} \log ^{-\beta}|x|\right) \\
+0\left(|x|^{-r-2}\right) \text { as }|x| \rightarrow \infty .
\end{gathered}
$$

This is a result due to Bosanquet and Linfoot [2].

Lemma 2. For $\alpha>0, \beta \geqq 0$ or $\alpha=0, \beta>0$ and

$$
r \geqq 0, x^{r} \bar{\lambda}_{1+\alpha+r, \beta}^{(r)}(x)=\sum_{i, j-0}^{r} B_{i j}^{r}(\alpha, \beta) \bar{\lambda}_{1+\alpha+r-i, \beta+j}(x),
$$

where the $B_{i j}^{r}$ are independent from $x$ and have the properties:

(i) $B_{i j}^{r}(\alpha, 0)=0$ for $j \geqq 1$;

(ii) $B_{r 0}^{r}(\alpha, \beta) \neq 0$;

(iii) $\sum_{i, j-0}^{r} B_{i j}^{r}(\alpha, \beta)=(-1)^{r} r !$.

Received January 19, 1960. 
The proofs of (i) and (ii) will be found in [3], Lemma 2, taking the imaginary parts of the equations there. Part (iii) follows immediately from the first part of the lemma and Lemma 1.

Lemma 3. For $n>0, \alpha=0, \beta>1$ or $\alpha>0, \beta \geqq 0$, and $r \geqq 0$,

$$
\begin{gathered}
\left(\frac{d}{d t}\right)^{r}\left\{2 B \pi^{-1} \sum_{\nu \leqq n}\left(1-\frac{\nu}{n}\right)^{\alpha} \log ^{-\beta}\left(\frac{C}{1-\frac{\nu}{n}}\right) \sin \nu t\right\} \\
=2 n^{r+1} \sum_{k=-\infty}^{\infty} \bar{\lambda}_{1+\alpha, \beta}^{(r)}[n(t+2 k \pi)] .
\end{gathered}
$$

Proof. Smith ([6], Lemma 6) has shown that for every odd, Lebesgue integrable function, $Z(t)$, of period $2 \pi$,

$$
\bar{S}_{\alpha, \beta}(Z, 0, n)=-2 n \int_{0}^{\infty} Z(t) \bar{\lambda}_{1+\alpha, \beta}(n t) d t .
$$

Since the right side of this equation can be written

$$
-2 n \int_{0}^{\pi} Z(t) \sum_{k=-\infty}^{\infty} \bar{\lambda}_{1+\alpha, \beta}[n(t+2 k \pi)] d t
$$

for every such $Z(t)$, the lemma is true for $r=0$. For $r \geqq 1$ the interchange of $(d / d t)^{r}$ and $\sum_{-\infty}^{\infty}$ is justified by uniform convergence.

The following lemma is a direct consequence of Lemma 3:

LEMMA 4. Let $f(x) \in C P[-\pi, \pi]$ and be of period $2 \pi$. For $n>0$ and $\alpha=0, \beta>1$ or $\alpha>0, \beta \geqq 0$,

$$
\bar{S}_{\alpha, \beta}^{r}(f, x, n)=2(-n)^{r+1} \int_{0}^{\pi} \psi(t) \sum_{k=-\infty}^{\infty} \bar{\lambda}_{1+\alpha, \beta}^{(r)}[n(t+2 k \pi)] d t .
$$

LEMMA 5. For $\alpha \geqq 0, \beta \geqq 0, n>0$ and $r \geqq 0$,

$$
n^{r+1} \int_{0}^{\infty} Q(t) \bar{\lambda}_{1+\alpha+r, \beta}^{(r)}(n t) d t=0,
$$

where $Q(t)$ is defined by (2).

Proof. If $r=0$, then $Q(t)=0$. For $r \geqq 1$ and $i=0,1, \cdots[r-1 / 2]$, the truth of the lemma follows from the equation:

$$
\int_{0}^{\infty} x^{r-1-2 i} \bar{\lambda}_{1+\alpha+r, \beta}^{(r)}(x) d x=0,
$$

which is easily verified by means of $r-1-2 i$ integrations by parts.

The final two lemmas of this section give the appropriate representation of the $n$th mean of $D_{r} C F S f(x)$. 
Lemma 6. Let $f(x) \in C_{\lambda} P[-\pi, \pi]$ and be of period $2 \pi$. Let $m, 0 \leqq$ $m \leqq \lambda+1$, be an integer for which $\Psi_{m}(t) \in L[0, \pi]$. Then, for $\alpha=m$, $\beta>1$ or $\alpha>m, \beta \geqq 0$ and $r \geqq 0$,

$$
\bar{S}_{\alpha+r, \beta}^{r}(f, x, n)=2(-n)^{r+1} \int_{0}^{\pi}[\psi(t)-Q(t)] \bar{\lambda}_{1+\alpha+r, \beta}^{(r)}(n t) d t+C_{r}+o(1)
$$

as $n \rightarrow \infty$, where

$$
\begin{gathered}
C_{r}=2 \pi^{-1}(-1)^{r+1} \int_{0}^{\pi} \psi(t)\left(\frac{d}{d t}\right)^{r}\left[\frac{1}{2} \operatorname{ctn} \frac{1}{2} t-t^{-1}\right] d t \\
+2 r ! \pi^{-1} \int_{\pi}^{\infty} t^{-r-1} Q(t) d t .
\end{gathered}
$$

Proof. It follows from Lemmas 4 and 5 that

$$
\begin{aligned}
\bar{S}_{\alpha+r, \beta}^{r}(f, x, n)= & 2(-n)^{r+1} \int_{0}^{\pi}[\psi(t)-Q(t)] \bar{\lambda}_{1+\alpha+r, \beta}^{(r)}(n t) d t \\
& +2(-n)^{r+1} \int_{0}^{\pi} \psi(t) \sum_{-\infty}^{\infty} \bar{\lambda}_{1+\alpha+r, \beta}^{(r)}[n(t+2 k \pi)] d t \\
& +-2(-n)^{r+1} \int_{\pi}^{\infty} Q(t) \bar{\lambda}_{1+\alpha+r, \beta}^{(r)}(n t) d t \\
= & I_{1}+I_{2}+I_{3} .
\end{aligned}
$$

Since the degree of $Q(t)$ is $r-1$, Lemma 1 shows that

$$
I_{3}=2 r ! \pi^{-1} \int_{\pi}^{\infty} t^{-r-1} Q(t) d t+o(1) .
$$

Let us define:

$$
\begin{aligned}
J(n, t)=2(-n)^{r+1} & \sum_{-\infty}^{\infty}\left\{\bar{\lambda}_{1+\alpha+r, \beta}^{(r)}[n(t+2 k \pi)]\right. \\
& \left.-(-1)^{r} r ! \pi^{-1}[n(t+2 k \pi)]^{-r-1}\right\} .
\end{aligned}
$$

Again appealing to Lemma 1 , we see that $\lim _{n \rightarrow \infty}(\partial / \partial t)^{j} J(n, t)=0$ uniformly for $t \in[0, \pi]$ and $j=0,1, \cdots, m$.

With the aid of the well-known cotangent expansion $I_{2}$ may be written:

$$
\begin{gathered}
I_{2}=\int_{0}^{\pi} \psi(t) J(n, t) d t+(-1)^{r+1} 2 \pi^{-1} \int_{0}^{\pi} \psi(t)\left(\frac{d}{d t}\right)^{r} \\
{\left[\frac{1}{2} \operatorname{ctn} \frac{1}{2} t-t^{-1}\right] d t .}
\end{gathered}
$$

But after $m$ integrations by parts, it is seen that

$$
\int_{0}^{\pi} \psi(t) J(n, t) d t=o(1) \text {. }
$$


The lemma now follows from equations (5), (6), (7), and (8).

A particular, but useful, case of Lemma 6 is

Lemma 7. Let $f(x) \in C_{\lambda} P[-\pi, \pi]$ and be of period $2 \pi$. If $g(t) \epsilon$ $C_{\mu} P[0, \pi]$, where $g(t)$ is defined by (3), then

$$
\begin{aligned}
\bar{S}_{\alpha, \beta}(g, 0, n)= & -2 n \int_{0}^{\pi} g(t) \bar{\lambda}_{1+\alpha, \beta}(n t) d t \\
& -2 \pi^{-1} \int_{0}^{\pi} g(t)\left(\frac{1}{2} \operatorname{ctn} \frac{1}{2} t-t^{-1}\right) d t+o(1)
\end{aligned}
$$

for $\alpha=1+\xi, \beta>1$ or $\alpha>1+\xi, \beta \geqq 0$, where $\xi=\min [\mu, \max (r, \lambda)]$.

The hypothese of Lemma 6 are fulfilled, because $\operatorname{tr}^{r} g(t) \in C_{\lambda} P[0, \pi]$ implies $G_{1+\xi}(t) \in L[0, \pi]$ by Lemma 6 of [3].

\section{Theorems.}

THEOREM 1. Let $f(x) \in C_{\lambda} P[-\pi, \pi]$ and be of period $2 \pi$. If there exist constants $\bar{a}_{r-1-2 i}, i=0,1, \cdots[r-1 / 2]$, such that

(i) $g(t) \in C_{\mu} P[0, \pi]$ for some integer $\mu$;

(ii) $\operatorname{CFSg}(0)=s(\alpha, \beta)$ for $\alpha=1+\xi, \beta>1$ or $\alpha>1+\xi, \beta \geqq 0$, where $\xi=\min [\mu, \max (r, \lambda)]$;

then $D_{r} C F S f(x)=S(\alpha+r, \beta), s=\pi^{-1} \int_{0}^{\pi} g(t) \operatorname{ctn}(1 / 2) t d t$ and

$$
S=-2 \pi^{-1} \int_{0}^{\pi} t^{-1} g(t) d t+C_{r},
$$

where $C_{r}$ is defined by equation (4).

THEOREM 2. Let $f(x) \in C_{\lambda} P[-\pi, \pi]$ and be of period $2 \pi$. If $D_{r} C F S f(x)=S(\alpha+r, \beta)$ for $\alpha=1+\lambda, \beta>1$ or $\alpha>1+\lambda, \beta \geqq 0$, then there exist constants $\bar{a}_{r-1-2 i}, i=0,1, \cdots[r-1 / 2]$, such that

(i) $g(t) \in C_{\mu} P[0, \pi]$ for some integer $\mu$ :

(ii) $C F S g(0)=s\left(\alpha^{\prime}, \beta^{\prime}\right)$, where

$\alpha^{\prime}=1+\xi, \beta^{\prime}>1$ if $1+\lambda \leqq \alpha<1+\xi$ or $\alpha=1+\xi, \beta \leqq 1 \alpha^{\prime}=\alpha$, $\beta^{\prime}=\beta$ if $\alpha=1+\xi, \beta>1$ or $\alpha>1+\xi, \beta \geqq 0$, and $\xi, s$ and $S$ have the values given in Theorem 1.

Before passing to the proofs of these theorems, let us observe that the existence of the constants $\bar{a}_{r-1-2 i}$ implies their uniqueness from the definition of $g(t)$. In fact, it can be shown that the $\bar{a}_{r-1-2 i}$ are given by

$$
D_{r-1-2 i} F S f(x)=\bar{a}_{r-1-2 i}(C), \quad i=0,1, \cdots\left[\frac{r-1^{1}}{2}\right] .
$$

1 Bosanquet ([1] , Theorem 1) has shown this for $f(x)$ Lebesgue integrable and $(C)$ replaced by Abel summability. 
In addition it can be shown that when $f(x) \in L$, the sum, $S$, of $D, C F S f(x)$ may be written

$$
S=-2 \pi^{-1} \int_{\rightarrow 0(C)}^{\infty} t^{-1} g(t) d t
$$

Proof of Theorem 1. That $s=-\pi^{-1} \int_{0}^{\pi} g(t) \operatorname{ctn}(1 / 2) t d t$ follows from the consistency of $(\alpha, \beta)$ summability and a result due to Sargent ([4], Theorem 3). Therefore, both $g(t) \operatorname{ctn}(1 / 2) t$ and $t^{-1} g(t)$ are $C P$ integrable over $[0, \pi]$.

From Lemma 7 we have

$$
\bar{S}_{\alpha, \beta}(g, 0, n)-s=-2 n \int_{0}^{\pi} g(t)\left[\bar{\lambda}_{1+\alpha, \beta}(n t)-(\pi n t)^{-1}\right] d t+o(1) .
$$

The left side of (9) is o(1) by hypothesis. By consistency equation (9) remains valid if $\alpha$ is replaced by $\alpha+r-i$ and $\beta$ by $\beta+j, i, j=$ $0,1, \cdots r$. Therefore,

$$
-2 n \int_{0}^{\pi} g(t) \sum_{i, j=0}^{r} B_{i j}^{r}(\alpha, \beta)\left[\bar{\lambda}_{1+\alpha+r-i, \beta+j}(n t)-(\pi n t)^{-1}\right] d t=o(1) .
$$

With the aid of Lemmas 2 and 6 , the last equation becomes

$$
\bar{S}_{\alpha+r, \beta}^{r}(f, x, n)=-2 \pi^{-1} \int_{0}^{\pi} t^{-1} g(t) d t+C_{r}+o(1) .
$$

This completes the proof of Theorem 1.

Proof of Theorem 2. Due to the length of this proof and its similarity to the proof of Theorem 2, ([3]), only a brief outline of the proof will be given.

Putting $Q(t)=0, \beta=0$ and $p>\alpha+r$ in Lemma 6 and integrating the right-hand side of the resulting equation $\lambda+1$ times, one can show that

$$
D_{r+\lambda+1} C F S\left(\Psi_{\lambda+1}, 0, n\right) \text { is summable }(C, p) \text {. }
$$

A result due to Bosanquet ([1], Theorem 1) and the stepwise procedure employed in the proof of Theorem 2 ([3], equations 18 through 22) lead to the conclusion: $t^{-r-1}[\psi(t)-Q(t)] \in C P[0, \pi]$ for an appropriate polynomial $Q(t)$, i.e., $t^{-1} g(t) \in C P[0, \pi]$. From this statement and a results due to Sargent ([4], Theorem 3), $g(t) \in C_{\mu} P[0, \pi]$ for some integer $\mu$ and $C F S g(0)=s(C)$, where $s=\pi^{-1} \int_{0}^{\pi} g(t) \operatorname{ctn}(1 / 2) t d t .^{3}$ series.

2 Ibid. The difference in sign is due to the distinction between allied and conjugate

${ }^{3}$ The $C P$ integrability of $g(t) \operatorname{ctn}(1 / 2) t$ is equivalent to that of $t^{-1} g(t)$. 
That $S$, the $(\alpha+r, \beta)$ sum of $D_{r} \operatorname{CFS} f(x)$, has the value

$$
-2 \pi^{-1} \int_{0}^{\pi} t^{-1} g(t) d t+C_{r}
$$

follows immediately from Theorem 1 and the consistency of the summability scale.

Thus, it remains to prove only the order relations $\left(\alpha^{\prime}, \beta^{\prime}\right)$ in (ii) of the theorem. A straightforward calculation using the representations in Lemmas 6 and 7, the properties of the $B_{i j}^{r}(\alpha, \beta)$ in Lemma 2, and the consistency of the summability scale applied to $D_{r} C F S f(x)$, leads to the following equations:

$$
\begin{array}{r}
\sum_{i, j=0}^{r} B_{i j}^{r}\left(\alpha^{\prime}+k, \beta^{\prime}\right)\left[\bar{S}_{\alpha^{\prime}+k+r-i, \beta^{\prime}+j}(g, 0, n)\right. \\
\left.-\pi^{-1} \int_{0}^{\pi} g(t) \operatorname{ctn} \frac{1}{2} t d t\right]=o(1),
\end{array}
$$

for $k=0,1,2, \cdots$.

The expression in brackets may be considered the $n$th mean of order $\left(\alpha^{\prime}+k+r-i, \beta^{\prime}+j\right)$ of a series formed from $C F S g(0)$ by altering the first term. Since this series is summable $(C)$ to 0 , then Lemma 8 [3] shows that $\operatorname{CFSg}(0)=s\left(\alpha^{\prime}, \beta^{\prime}\right)$.

The following theorem gives a sufficient condition for the $(\alpha, \beta)$ summability of $C F S g(0)$ for $\beta \neq 0$. Since the proof follows the usual lines for Riesz summability, it is omitted.

THEOREM 3. Let $g(t)$ be an odd function of period $2 \pi$. If $t^{-1} g(t) \in C_{k} P[0, \pi]$, where $k$ is a non-negative integer, then

$$
\operatorname{CFSg}(0)=-\pi^{-1} \int_{0}^{\pi} g(t) \operatorname{ctn} \frac{1}{2} t d t(1+k, \beta), \beta>1 .
$$

As an application of these theorems it can be shown that

$$
D_{r} \operatorname{CFSf}(0, m)=S(1+m+2 r, \beta), \beta>1,
$$

where $f(x ; m)$ is either $x^{-m} \sin x^{-1}$ or $x^{-m} \cos x^{-1}, m=0,1,2, \cdots$.

The following results may be deduced from Theorems 1 and 2 . It is assumed that $f(x) \in C_{\lambda} P[-\pi, \pi]$ and is of period $2 \pi$. The values of $S$ and $s$, when either exists, and $\xi$ are given in Theorem 1.

(A). If $g(t) \in C_{\mu} P[0, \pi]$, then for $\alpha=1+\xi, \beta>1$ or $\alpha>1+\xi$, $\beta \geqq 0, D_{r} C F S f(x)=S(\alpha+r, \beta)$ if and only if $C F S g(0)=s(\alpha, \beta)$.

(B). For $\alpha=1+\max (r, \lambda), \beta>1$ or $\alpha>1+\max (r, \lambda), \beta \geqq 0$, $D_{r} C F S f(x)=S(\alpha+r, \beta)$ if and only if $g(t) \in C P[0, \pi]$ and $C F S g(0)=$ $s(\alpha, \beta)$. 
These results generalize, to various degrees, results obtained by Takahashi and Wang [7] and Bosanquet [1].

A weak, but none the less interesting, form of these results is

(C). If $f(x) \in C P[-\pi, \pi]$ and is of period $2 \pi$, then in order that $D_{r} C F S f(x)$ be summable $(C)$, it is necessary and sufficient that $g(t) \in C P[0, \pi]$ and $C F S g(0)$ be summable $(C)$.

\section{REFERENCES}

1. L. S. Bosanquet, On the derived allied series of a Fourier series, Proc. London Math. Soc. (2), 49 (1947), 63-76.

2. L. S. Bosanquet and E. H. Linfoot, Generalized means and the summability of Fourier series, Quart. Journal of Math. (Oxford), 2 (1931), 207-229.

3. B. J. Boyer, On the summability of derived Fourier series, Pacific J. Math. (To be published.)

4. W. L. C. Sargent, On the summability $(C)$ of allied series, Proc. London Math. Soc., 50 (1949), 330-348.

5. A. H. Smith, On the summability of derived conjugate series of the Fourier-Lebesgue type, Bull. Amer. Math. Soc., 40 (1934), 406-412.

6. - Summability of conjugate Fourier series, Duke Math. Journal. 4 (1938), $270-276$.

7. T. Takahashi and F. T. Wang, Some notes on trigonometric series, Tohoku Math. Journal, 41 (1935), 169-187.

FLORIDA STATE UNIVERSITY 



\section{PACIFIC JOURNAL OF MATHEMATICS}

\section{EDITORS}

David GILbarg

Stanford University

Stanford, California

\section{F. H. BRowneLL}

University of Washington

Seattle 5, Washington

\section{A. L. Whiteman}

University of Southern California Los Angeles 7, California

\section{J. PAIGe}

University of California

Los Angeles 24, California

\section{ASSOCIATE EDITORS}
E. F. BECKENBACH
T. M. CHERRY
D. DERRY

\author{
E. HEWITT \\ A. HORN \\ L. NACHBIN
}

\author{
M. OHTSUKA \\ H. L. ROYDEN \\ M. M. SCHIFFER
}

E. SPANIER

E. G. STRAUS

F. WOLF

\section{SUPPORTING INSTITUTIONS}

\author{
UNIVERSITY OF BRITISH COLUMBIA \\ CALIFORNIA INSTITUTE OF TECHNOLOGY \\ UNIVERSITY OF CALIFORNIA \\ MONTANA STATE UNIVERSITY \\ UNIVERSITY OF NEVADA \\ NEW MEXICO STATE UNIVERSITY \\ OREGON STATE COLLEGE \\ UNIVERSITY OF OREGON \\ OSAKA UNIVERSITY \\ UNIVERSITY OF SOUTHERN CALIFORNIA
}

\author{
STANFORD UNIVERSITY \\ UNIVERSITY OF TOKYO \\ UNIVERSITY OF UTAH \\ WASHINGTON STATE COLLEGE \\ UNIVERSITY OF WASHINGTON \\ AMERICAN MATHEMATICAL SOCIETY \\ CALIFORNIA RESEARCH CORPORATION \\ HUGHES AIRCRAFT COMPANY \\ SPACE TECHNOLOGY LABORATORIES \\ NAVAL ORDNANCE TEST STATION
}

\footnotetext{
Mathematical papers intended for publication in the Pacific Journal of Mathematics should be typewritten (double spaced), and the author should keep a complete copy. Manuscripts may be sent to any one of the four editors. All other communications to the editors should be addressed to the managing editor, L. J. Paige at the University of California, Los Angeles 24, California.

50 reprints per author of each article are furnished free of charge; additional copies may be obtained at cost in multiples of 50 .
}

The Pacific Journal of Mathematics is published quarterly, in March, June, September, and December. The price per volume (4 numbers) is $\$ 12.00$; single issues, $\$ 3.50$. Back numbers are available. Special price to individual faculty members of supporting institutions and to individual members of the American Mathematical Society: $\$ 4.00$ per volume; single issues, $\$ 1.25$.

Subscriptions, orders for back numbers, and changes of address should be sent to Pacific Journal of Mathematics, 2120 Oxford Street, Berkeley 4, California.

Printed at Kokusai Bunken Insatsusha (International Academic Printing Co., Ltd.), No. 6, 2-chome, Fujimi-cho, Chiyoda-ku, Tokyo, Japan.

PUBLISHED BY PACIFIC JOURNAL OF MATHEMATICS, A NON-PROFIT CORPORATION

The Supporting Institutions listed above contribute to the cost of publication of this Journal, but they are not owners or publishers and have no responsibility for its content or policies. 


\section{Pacific Journal of Mathematics}

\section{Vol. 10, No. $4 \quad$ December, 1960}

M. Altman, An optimum cubically convergent iterative method of inverting a linear bounded operator in Hilbert space . . . . . . . . . . . . . . . . . . . . . . . . . . 1107

Nesmith Cornett Ankeny, Criterion for rth power residuacity ................. 1115

Julius Rubin Blum and David Lee Hanson, On invariant probability measures I . . . . . 1125

Frank Featherstone Bonsall, Positive operators compact in an auxiliary topology ..... 1131

Billy Joe Boyer, Summability of derived conjugate series . . . . . . . . . . . . . . . . 1139

Delmar L. Boyer, A note on a problem of Fuchs . . . . . . . . . . . . . . . . . 1147

Hans-Joachim Bremermann, The envelopes of holomorphy of tube domains in infinite

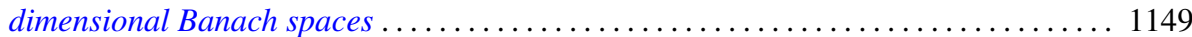

Andrew Michael Bruckner, Minimal superadditive extensions of superadditive

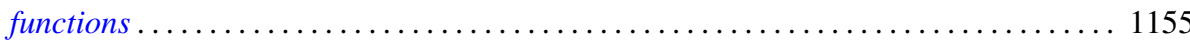

Billy Finney Bryant, On expansive homeomorphisms .................... 1163

Jean W. Butler, On complete and independent sets of operations in finite algebras . . . . . 1169

Lucien Le Cam, An approximation theorem for the Poisson binomial distribution ...... 1181

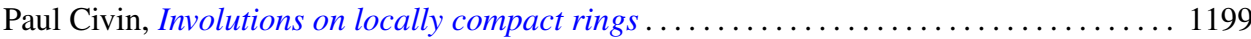

Earl A. Coddington, Normal extensions of formally normal operators . . . . . . . . . 1203

Jacob Feldman, Some classes of equivalent Gaussian processes on an interval ........ 1211

Shaul Foguel, Weak and strong convergence for Markov processes . . . . . . . . . . . 1221

Martin Fox, Some zero sum two-person games with moves in the unit interval ........ 1235

Robert Pertsch Gilbert, Singularities of three-dimensional harmonic functions . . . . . . . 1243

Branko Grünbaum, Partitions of mass-distributions and of convex bodies by

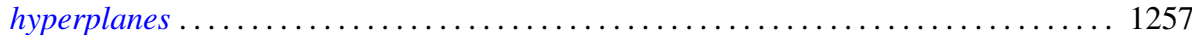

Sidney Morris Harmon, Regular covering surfaces of Riemann surfaces ........... 1263

Edwin Hewitt and Herbert S. Zuckerman, The multiplicative semigroup of integers

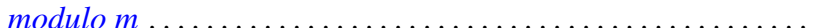

Paul Daniel Hill, Relation of a direct limit group to associated vector groups . ......... 1309

Calvin Virgil Holmes, Commutator groups of monomial groups . .

James Fredrik Jakobsen and W. R. Utz, The non-existence of expansive homeomorphisms

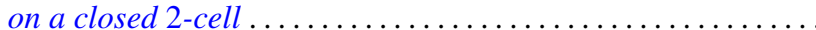

John William Jewett, Multiplication on classes of pseudo-analytic functions . . . . . . . 1323

Helmut Klingen, Analytic automorphisms of bounded symmetric complex domains . . . . 1327

Robert Jacob Koch, Ordered semigroups in partially ordered semigroups . . . . . . . . 1333

Marvin David Marcus and N. A. Khan, On a commutator result of Taussky and

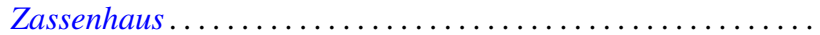

John Glen Marica and Steve Jerome Bryant, Unary algebras......

Edward Peter Merkes and W. T. Scott, On univalence of a continued fraction . . . . . . . 1361

Shu-Teh Chen Moy, Asymptotic properties of derivatives of stationary measures . . . . . 1371

John William Neuberger, Concerning boundary value problems . . . . . . . . . . . 1385

Edward C. Posner, Integral closure of differential rings . . . . . . . . . . . . . . . . . 1393

Marian Reichaw-Reichbach, Some theorems on mappings onto . . . . . . . . . . . . . 1397

Marvin Rosenblum and Harold Widom, Two extremal problems . . . . . . . . . . . . . . . . 1409

Morton Lincoln Slater and Herbert S. Wilf, A class of linear differential-difference

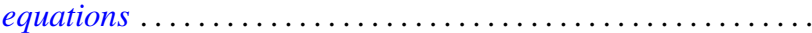

Charles Robson Storey, Jr., The structure of threads . . . . . . . . . . . . . . . . . . 1429

J. François Treves, An estimate for differential polynomials in $\partial / \partial z_{1},, \cdots, \partial / \partial z_{-} n \ldots \ldots 1447$

J. D. Weston, On the representation of operators by convolutions integrals . . . . . . . . 1453

James Victor Whittaker, Normal subgroups of some homeomorphism groups ......... 1469 